\title{
Interactive comment on "Multi-decadal Records of Stratospheric Composition and their Relationship to Stratospheric Circulation Change" by Anne R. Douglass et al.
}

\section{Anonymous Referee \#1}

Received and published: 6 July 2017

Douglass et al. analyze the representation of transport and mixing processes in MERRA-2 by comparing CTM simulations of long-lived trace gases with ground-based and satellite observations. The use of different trace gas data sets from multiple instruments combined with investigations of mean age and fractional release allows to evaluate how realistic the MERRA-2 circulation is over the 1990-2015 time period. The article is very well written and of interest for the ACP readership, since it provides insights into important aspects of modern reanalysis data sets. I recommend publication after minor revisions.

General comments: 
1) The relation between mean age of air and fractional release does not become clear without being familiar with prior studies. Here, the authors could greatly enhance the understandability of their argumentation by providing better explanations and/or examples. This is all the more important since the main conclusions (impact of horizontal mixing on MERRA-2 traces gas simulations) are partially drawn from the relationship. Statements in section 4.1.2 need more detailed information, e.g., Page 9, line 1: where does mixing lead to an increase of age? Only in the tropics? Or in the whole stratosphere? Why does this not change the fractional release? Also, it is hard to follow the argumentation since once of the major figures is not clear: Do figures $2 c$ and $d$ show the fractional release (as indicated in the caption and text) or the change of the fractional release (as indicated in the labeling of the $y$-axis)?

2) It does not become clear why the GEOSCCM simulations are included. It seems that all the conclusions can be made without the use the CCM model runs, at least they are not mentioned in the discussion or conclusion section at all.

3) There seems to be some offset in the timing of the different characteristics described in the text. The shift in agreement between observations and CTM simulations of $\mathrm{HNO} 3 / \mathrm{HCl}$ seems to appear between 2000 and 2005. However, the largest changes of fractional release relative to age of air seem to appear between 1990 and 1995 (if I understand Figure 2c correctly). Later in the manuscript this discrepancy between the two analyses is avoided by talking about a shift around 2000. Please clarify.

Minor comments:

1) Page 6, line 24: MERRA should be MERRA-2

2) Page 11, line 21-27: Could this shift occurs also without a change in the fractional release - mean age comparison due to too old/young age in MERRA-2 before 2000 ? Should it be Figure $2 \mathrm{c}$ instead of $2 \mathrm{~b}$ ?

Interactive comment on Atmos. Chem. Phys. Discuss., https://doi.org/10.5194/acp-2017-401, 
Interactive comment 